\title{
ANALYSIS OF CIRCUITS WITH OPERATIONAL AMPLIFIERS
}

\author{
Anton Andonov \\ University of Chemical Technology and Metallurgy, Bulgaria \\ 8 KI.Ohridski, 1756 Sofia, Bulgaria \\ e-mail: andonov@uctm.edu
}

\begin{abstract}
The method and the dependencies for transformation of parallelly connected active bipolars into one equivalent (theorem of Millman) during the analysis of single-line analogy circuits with operational amplifiers is presented.Three examples of the application of the theorem of Millman for determining certain parameters and dependencies for circuits of measuring amplifiers and converters are considered.
\end{abstract}

Keywords: operational amplifiers, theorem of Millman, measuring converter.

\section{INTRODUCTION}

Two approaches are basically used for the analysis of different circuits with operational amplifiers (OA). The first one is based on the theory of feedback (FB). The second approach makes use of the laws of Kirhoff, considering OA to be ideal.

The present work examines the application of the method for transformation of parallelly connected active bipolars (voltage generators) in one equivalent [1,7]. According to it, an electric circuit, consisting of $n$ parallelly connected branches with conductivities $Y_{1}, Y_{2}, \ldots$, $Y_{n}$ and voltage sources respectively $e_{1}, e_{2}, \ldots, e_{n} \ldots$ (Figure 1) can be replaced with an equivalent source of voltage Uoa and its own resistance Z:

$$
Z=\frac{1}{\sum_{k=1}^{n} Y_{k}}, \quad U_{O A}=\frac{\sum_{k=1}^{n} e_{k} Y_{k}}{\sum_{k=1}^{n} Y_{k}}=\frac{\sum_{k=1}^{n} Y_{k} U_{O k}}{\sum_{k=1}^{n} Y_{k}}
$$

Where $e_{k}=\operatorname{Uok}(k=1,2, \ldots, n)$.

The sum (1) is algebric and the voltage signs are determined against a common reper, e.g. in respect to junctions $O$ and $A$. The expression is valid even when part of the parallel branches are passive. Then the value of the respective voltage is taken to be equal to zero [1]. This dependency (theorem of Millman) can be used for determining some parameters of single-line analogy circuits with OA. Such circuits find wide application in the systems of automation as measuring amplifiers, measuring converters, various regulators, etc. $[4,5,6$, $8,9,10]$. Different correctional circuits as well as circuits for FB, generally with RC elements, participate in them. 


\section{IRTITE} Ipplied Researleches in Technics, Technologies and Eductation Journal of the Faculty of Technics and Technologies, Trakia University https://sites.google.com/a/trakia-uni.bg/artte/

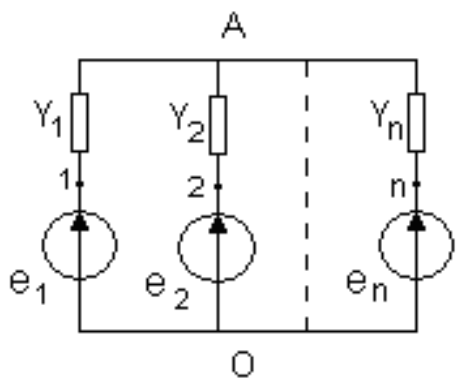

Figure 1. Parallelly connected active bipolars

In all cases $O A$ are considered to be ideal - with amplification coefficient of voltage without FB $K_{U} \rightarrow \infty$, with input impedance $Z_{i} \rightarrow \infty$ and input current $I_{1} \rightarrow 0$, with output impedance $Z_{0} \rightarrow 0 \quad$ (with open circuit for FB), voltage and current of asymmetry $u_{10} \rightarrow 0$ and $i_{10} \rightarrow 0$ $[2,3,4,6,9,10]$.

It is characteristic for AO that it "estimates" the status of its output and input and with the assistance of the external circuit for FB, it passes voltage from the output to the input in such a way that as a result the difference between the voltage of the output and input becomes zero $[2,3,4,6]$.

\section{RESULTS AND DISCUSSION}

Figure 2 shows the scheme of an inverting amplifier with a T-shaped divider in the circuit for FB [9]. All potentials in the marked junctions are considered against the common "mass" junction $\mathrm{O}$. According to the above mentioned characteristics of $\mathrm{OA}$ and the principle of "conventional ground" $[2,3,4,6]$, the potentials ar the entries of $\mathrm{OA}$ are equal, i.e. $V_{a}=V_{b}=$ 0 . According to the theorem of Millman (1) we can write down:

$$
v_{b}=\frac{\frac{V_{i}}{R_{1}}+\frac{V_{a}}{R_{2}}}{\frac{1}{R_{1}}+\frac{1}{R_{2}}}=0
$$

$$
V a=\frac{\frac{V_{b}}{R_{2}}+\frac{V_{0}}{R_{3}}}{\frac{1}{R_{2}}+\frac{1}{R_{3}}+\frac{1}{R_{4}}}
$$

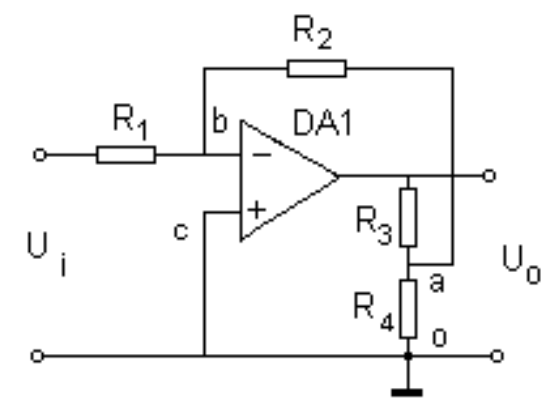

Figure 2. Inverting amplifier with a T-shaped divider in the circuit for FB

When (3) is solved against $V_{a}$ and is equalized to (4), it is easy to obtain the expression for the amplification coefficient of voltage for the circuit: 


\section{IRTTIE} Ipplied Researrches in Technics, Technologies and Bducition Journal of the Faculty of Technics and Technologies, Trakia University https:///ites.google.com/a/trakia-uni.bg/artte/

$$
K=\frac{V_{0}}{V i}=-\frac{R_{2} R_{3}+R_{3} R_{4}+R_{2} R_{4}}{R_{1} R_{4}}=-\frac{1}{R_{1}}\left(R_{2}+R_{3}+\frac{R_{2} R_{3}}{R_{4}}\right)
$$

Figure 3 shows the scheme of a measuring differential amplifier with high input resistance, which can work in intensive disturbing signals (broom, impulse interference, etc.), appearing single-phase at both entries [10]. The amplification coefficient of this circuit can be regulated by modifying $R_{3}$. Similarly to the previous scheme there is an equality of the potentials at the entries of the OA, i.e. $V_{a}=V_{c}$ and $V_{b}=V_{e}$ whereas

$$
U_{i}=V_{a}-V_{b}
$$

According to dependency (1) for the case is found:

$$
V_{a}=V_{c}=\frac{\frac{V_{d}}{R_{2}}+\frac{V_{e}}{R_{3}}}{\frac{1}{R_{1}}+\frac{1}{R_{2}}+\frac{1}{R_{3}}}, \quad V_{b}=V_{e}=\frac{\frac{V_{d}}{R_{2}}+\frac{V_{c}}{R_{3}}+\frac{U_{0}}{R_{3}}}{\frac{1}{R_{1}}+\frac{1}{R_{2}}+\frac{1}{R_{3}}}
$$

Replacing the expressions (7) in (6) and provided that $R_{4}=R_{2}$ and $R_{5}=R_{1}$, after ordinary algebric transformations the following is obtained for the amplification coefficient:

$$
K=\frac{U_{0}}{U_{i}}=1+R_{1}\left(\frac{2}{R_{3}}+\frac{1}{R_{2}}\right)
$$

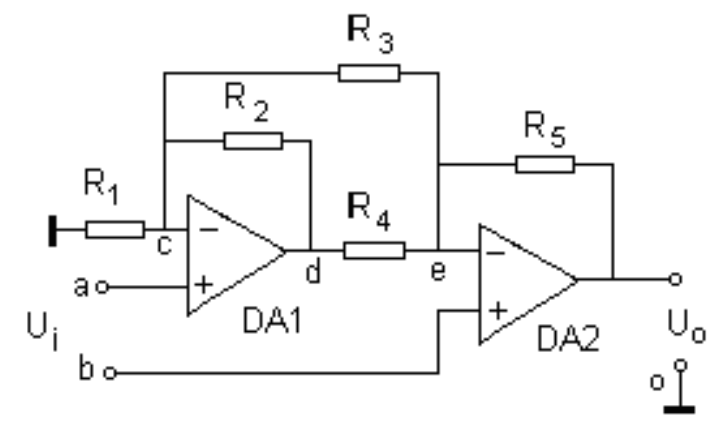

Figure3. Measuring differential amplifier

The following scheme (Figure 4) finds application in automation as a proportional-integraldifferential (PID) regulator as well as in the analog measuring technique for differentiating and separating rapidly-changing signals, finding the average of alternating quantities, etc. [6]. On the conductivities of the input circuit $Y_{1}$ and the FB circuit $Y_{2}$ in operational form [7], it can be written down:

$$
Y_{1}=\frac{1}{R_{1}}+p C_{1}, \quad Y_{2}=\frac{1}{R_{2}+\frac{1}{p C_{2}}}
$$




\section{IRTIIE}

Ipplied Researreches in Technics, Technologies and Bdurition Journal of the Faculty of Technics and Technologies, Trakia University https://sites.google.com/a/trakia-uni.bg/artte/

According to the considered features of $\mathrm{OA}$, it follows that $V_{a}=V_{b}=0$. Then for junction $a$ according to (1) it is obtained:

$$
\frac{U_{i}(p)\left(\frac{1}{R_{1}}+p C_{1}\right)+\frac{U_{0}(p)}{R_{2}+\frac{1}{p C_{2}}}}{\frac{1}{R_{1}}+p C_{1}+\frac{1}{R_{2}+\frac{1}{p C_{2}}}}=0
$$

When (10) is solved against $U_{0}(p)$ we obtain the link between the output and input voltage in operational form:

$$
U_{0}(p)=-\left[\left(\frac{R_{2}}{R_{1}}+\frac{C_{1}}{C_{2}}\right)+p R_{2} C_{1}+\frac{1}{p R_{1} C_{2}}\right] U_{i}(p)
$$

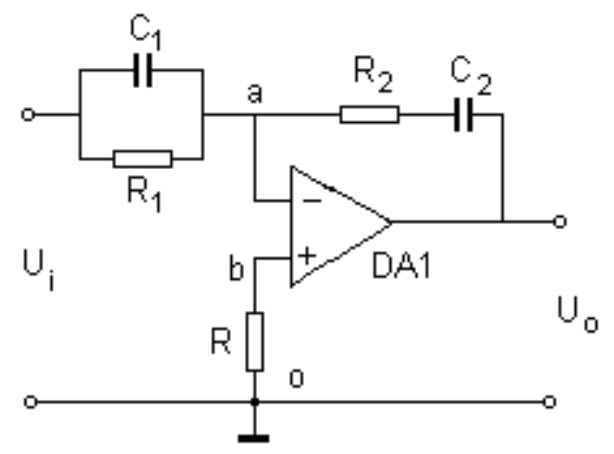

Figure 4 Proportional-integral-differential regulator

After the reverse transformation of Laplas it is easy to obtain the link between the originals of the voltages:

$$
U_{O}(t)=-\left[\left(\frac{R_{2}}{R_{1}}+\frac{C_{1}}{C_{2}}\right) U_{i}(t)+R_{2} C_{1} \frac{d U_{i}(t)}{d t}+\frac{1}{R_{1} C_{2}} \int_{0}^{t} U_{i}(t) d t\right]
$$

\section{CONCLUSION}

The use of the method and the dependencies for transformation of parallely connected active bipolars in one equivalent (theorem of Millman) can considerably simplify the analysis of singleline analogy schemes with $\mathrm{OA}$. The proposed approach can be applied for obtaining certain parameters and dependencies for measuring converters, regulators, etc. It is particularly helpful in more complex schemes with more than one OA. 


\section{ARTTE $Y$ Y}

Ipplied Resseirlores in Technics, Technologies and Educration Journal of the Faculty of Technics and Technologies, Trakia University https://sites.google.com/a/trakia-uni.bg/artte/

\section{REFERENCES}

[1] Farhi S.\& Papazov S. (1987). Teoretichna elektrotehnika (chast 1).Tehnika, Sofia,1987 (in Bulgarian), p.633.

[2] Floyd T.\& Buchla D. (1998). Basic operational amplifiers and linear integrated circuits, Prentice Hall, 1998, p. 593.

[3] Graeme J. (1999). Amplifier applications of Op-Amps., McGraw-Hill,1999, p. 286.

[4] Horowitz P.\&.Hill W.(1989). Art of electronics. Camridge university press, 1989, p.1125.

[5] Huijsing J., van de Plassche R.\& Sansen W. (editors) (1993). Analog Circuit DesignOperational Amplifiers, Analog to Digital Convertors, Analog Computer Aided Design. Kluwer Academic Publishers, Boston ,1993, p. 452.

[6] Kazmerkovskij M.\& Vujcak A. (1983). Shemy upravlenia i izmerenia v promishlennoj elektronike. Energoatomizdat, Moskow,1983 (in Russian), p. 224.

[7] Kontorovich M. (1975). Operacionnoe ischislenie i processy w elektricheskih cepjah, Sovetskoe radio, Moskow, 1975 (in Russian), p. 365.

[8] Nerguizian V., Rafaf M.\& Nerguizian C. (2005). Electric and electronic circuit analysis with Millman theorem. Proceedings of the 9th WSEAS International Conferense on Circuits, Athens, Greece, july 11-13, 2005, 497-091.

[9] Shojlev H.\& Mihajlov M. (1981). Sbornik prilojni shemi s operacionni usilvateli. Tehnika, Sofia, 1981 (in Bulgarian), p.184.

[10] Williams A. (editor).(1987). Primenenie integralnih shem - 1. ( (1987). Mir, Moskow,1987 (in Russian), p.432. 